Article

\title{
Fuzzy Logic-Based Prediction of Drilling-Induced Temperatures at Varying Cutting Conditions along with Analysis of Chips Morphology and Burrs Formation
}

\author{
Asim Ahmad Riaz 1,*(D), Riaz Muhammad ${ }^{2}$, Naveed Ullah 1, Ghulam Hussain ${ }^{3, *}$, Mohammed Alkahtani 4,5 \\ and Waseem Akram ${ }^{6}$ (D) \\ 1 Department of Mechanical Engineering, University of Engineering \& Technology, Peshawar 25000, Pakistan; \\ naveedullah@uetpeshawar.edu.pk \\ 2 Mechanical Engineering Department, College of Engineering, University of Bahrain, Isa Town 32038, Bahrain; \\ rmuhammad@uob.edu.bh \\ 3 Faculty of Mechanical Engineering, Ghulam Ishaq Khan Institute of Engineering Sciences and Technology, \\ Topi 23460, Pakistan \\ 4 Industrial Engineering Department, College of Engineering, King Saud University, \\ Riyadh 11421, Saudi Arabia; moalkahtani@ksu.edu.sa \\ 5 Raytheon Chair for Systems Engineering (RCSE), Advanced Manufacturing Institute, King Saud University, \\ Riyadh 11421, Saudi Arabia \\ 6 Department of Mechanical Engineering, International Islamic University (IIU), Islamabad 44000, Pakistan; \\ waseem.akram@iiu.edu.pk \\ * Correspondence: engr.asim@uetpeshawar.edu.pk (A.A.R.); ghulam.hussain@giki.edu.pk (G.H.)
}

check for updates

Citation: Riaz, A.A.; Muhammad, R.; Ullah, N.; Hussain, G.; Alkahtani, M.; Akram, W. Fuzzy Logic-Based Prediction of Drilling-Induced Temperatures at Varying Cutting Conditions along with Analysis of Chips Morphology and Burrs Formation. Metals 2021, 11, 277. https://doi.org/10.3390/met11 020277

Academic Editors: Badis HADDAG Received: 6 January 2021

Accepted: 30 January 2021

Published: 5 February 202

Publisher's Note: MDPI stays neutral with regard to jurisdictional claims in published maps and institutional affiliations.

Copyright: (c) 2021 by the authors. Licensee MDPI, Basel, Switzerland. This article is an open access article distributed under the terms and conditions of the Creative Commons Attribution (CC BY) license (https:/ / creativecommons.org/licenses/by/ $4.0 /)$

\begin{abstract}
Friction and plastic deformation at the tool-chips interaction during a dry drilling process results in temperature rise and promotes tool wear and surface roughness. In most of the components produced in industries, a drilling process is used to make a hole for final assembly. Therefore, knowledge of temperatures produced during drilling operation at various machining input parameters is required for the best quality product. A fuzzy logic-based algorithm is developed to predict the temperature generated in the drilling process of AISI 1018 mild steel. The algorithm used speed and feed rate of the drill bit as input parameters to the fuzzy domain. A set of rules was used in the fuzzy domain to predict maximum temperature produced in the drilling process. The developed algorithm is simulated for various input speed and feed rate parameters and was verified through the maximum temperature measured during drilling of the studied material at selected speed-feed combinations. Experiments were conducted to validate the results of developed fuzzy logic-based algorithm by using non-contact infrared pyrometer for drilling of AISI 1018 steel. A good agreement between the predicted and experimentally measured maximum temperature was observed with an error less than $6 \%$. It is found that temperature increases with increase in cutting speed and feed rate. Size of roll back burr formation at the hole perimeter significantly increases with increase in drill speed and feed rate. Segmental continuity in spiral or helix chips morphology is more at low feed and high cutting speed. Chip radius increases with increase in feed rate and results in damaging of the machined surface and causes burr formation while the radius decreases with cutting speed along with improved hole surface finish.
\end{abstract}

Keywords: fuzzy logic algorithm; machining; temperature; drilling; infrared pyrometer; fuzzy inference system

\section{Introduction}

AISI 1018 steel belongs to the steel class of material kingdom and has a properties profile compatible with most of the engineering applications. Due to excellent metallurgical and mechanical properties, this alloy is extensively used in making gears, shafts, spindles, pins, rods, sprocket chains, and other machine tools and components. It has good machinability, weldability, and mechanical properties [1]. 
Drilling is one of the principal machining processes and is used to create holes. In the aerospace and automobile sectors, conventional drilling is economically viable to create holes in mechanical parts/geometries [2]. Surface finish and tolerance are the valued characteristics of the drilled hole. Air vehicles and fast-moving objects are subjected to constant vibration and shock loads where fastener holes are prone to stress concentration and fatigue loads [3]. Fatigue load compromises reliability of aircraft and other vehicles. Region of fastener holes give rise to stress concentration and eventually leads to fatigue cracks and causes structure failures. Fatigue and stress concentration factor are the function of drilled hole quality [4]. In the product development process, the activity of drilling holes in the part occurs in the final stages where poor hole finish may result in part/product rejection. The part rejection is costly and can be minimized if the required tool and optimal process parameters for drilling are selected [5]. During drilling operations, high friction at the tool-chips interface degrades surface finish and leads to heat generation, tool wear, and increase in cutting forces.

Fuzzy logic is one of the artificial intelligence techniques which is based on mathematical modeling and equations to map and simulate engineering problems [6]. This method has powerful and intelligent reasoning capabilities with less bounding rules and multivalued logic [7]. Literature reveals the use of fuzzy logic modeling to validate the machining performance and behavior. Aamir et al. used fuzzy logic approach to predict hole size and surface roughness in multi-hole drilling [8]. Ramesh et al. used fuzzy inference system to predict and validate the machining performance of titanium alloy, i.e., surface roughness, cutting pressure, and tool wear [9]. Fuzzy logic data selection for drilling process of AISI steel is developed by Hashmi et al. [10]. Jitesh et al. [11] developed an adaptive neuro fuzzy inference system (ANFIS) model for the prediction of tool-conditions based on hole quality during micro-drilling. Other research studies reported the applications of fuzzy inference system (FIS) to predict thrust forces, cutting pressures, torque, surface roughness, tool wear, tool life, hole size, and delamination [12-15]. In this study, maximum drilling-induced temperature during the drilling process at varying drilling conditions is predicted using FIS while considering cutting speed and feed rate as input parameters to the fuzzy domain.

Most of cutting energy in drilling is utilized to separate material from a workpiece in the form of chips and overcome friction losses. In conventional dry drilling operation, heat is generated due to plastic deformation of the workpiece materials and friction losses between the tool-workpiece interaction zone. The process zone temperature is a function of various parameters; however, the most dominant parameters are workpiece/tool materials, tool geometry, and the cutting conditions. The high process zone temperature, in addition to high cutting forces, accelerates the tool wear and degrades the hole quality $[16,17]$. International community is interested in more sustainable and greener manufacturing methods for future generation and dry cutting is gaining popularity on standard flooding machining due to low cost and reducing environmental effects. The main advantage of dry drilling is to get rid of the additional cost associated with the disposal of coolant used in machining operations. On the other hand, the high temperature produced at the process zone accelerates the tool wear in dry machining as compared to coolant-based machining operations [18]. Traditionally, tool wear is reduced with proper emulsion, coating, and other coolant which results in lowering temperature under varying drilling conditions. Therefore, downtimes in production and machining setups associated with tool failure can be minimized by having proper knowledge of heat generated in drilling operation [19].

In drilling processes, the heat generated in the process zone is primarily contributed by the plastic deformation of the parent material and friction between the tool and workpiece interaction zone. The effect of tool speed and feed rate on process induced temperature in drilling processes is studied by R. Muhammad et al. and they concluded that cutting speed majorly contributes to heat generation [20]. Due to temperature increase at the toolworkpiece interface during drilling, the diffusion mechanism is noticed in Al-2219 alloy in which the aluminum start adhesion and sticking with tool edges [21,22]. Temperature rise 
during dry drilling in composite materials is experimentally studied by S. Rawat and $\mathrm{H}$. Attia and they found that rate of temperature rise increases from $5-63^{\circ} \mathrm{C} / \mathrm{sec}$ if feed rate changes from $20-200 \mu \mathrm{m} / \mathrm{rev}$ [23]. The temperature while drilling a hole is measured using infrared radiation pyrometer. Temperature significantly shoots near the bottom of the hole during drilling. Masahiko et al. found that during drilling of carbon steel, temperature increases with increasing depth and at a depth of $10 \mathrm{~mm}$, the maximum temperature rise was $340{ }^{\circ} \mathrm{C}$ [24]. Dewes et al. [25] recorded temperature variation at the tool-job interface using an infrared camera and thermocouples. Likewise, infrared pyrometer is used to find the heat transfer model for temperature distribution along the milling path during chips' formation. Bagci et al. [26] studied temperature profile during step wise and continuous drilling of AISI 1040 steel while changing speed and feed rate of the drill bit. It is found that temperature increases significantly with changing speed as compared to feed during continuous drilling. To limit rise in temperature due to frictional heat and tool wear due to built-up edge (BUE), the most common method is to use coolant during drilling. Cutting fluid cost and environmental pollution promotes the development of alternate methods, i.e., minimum quantity lubrication method, ultrasonic vibration, etc. [27]. Minimum Quantity Lubrication (MQL) reduces the drilling force and improves drill hole precision in AISI 1040 steel as compared to dry drilling using High Speed Steel drill bit [28]. Another investigation also shows that drilling with MQL and coated drill bits reduces temperature rise during tool-chips interaction [29]. Braga et al. [30] showed that the bulk quantity of chips are stuck in the flute and cutting edges during wet drilling at higher feed rates. Maruda et al. [31] compared MQL with dry drilling for chips geometry and surface roughness and found that short spiral chip in MQL has less negative effect on hole finishing.

In dry drilling, frictional forces are greater during chips' shearing which effect the chip thickness, size, and morphology. Built-up edge (BUE) and discontinuous chips formation stick and adhere with tool edges and effect hole surface [32,33]. Chips with built-up edges form during dry drilling which increase the required drilling forces for making holes [34]. Chips morph type in drilling has great impact on surface finishing. Chip morphology variates in drilling zone at varying cutting conditions. Continuous chips and BUE are not desirable in drilling as they fill the chute of the drill bit and scratch the machined hole. It is more at low feed rates. It is preferable to form segmented chips instead of continuous chips during drilling. Surface roughness is less in continuous straight chips compared to helical coil shape $[35,36]$. It is observed that with increase in feed rate during drilling, surface finish of the hole degrades significantly [37]. Workpiece ductility has great influence on burrs formation. Higher burrs formation will occur if the material is more ductile. To reduce burrs formation in ductile workpiece, higher rotational speeds are preferred. In addition, increase in feed rate causes more burr formation due to the plowing action of the drill bit [38]. Surface roughness and tool thrust decrease with increase in cutting speed during drilling operation. Broken chips during drilling improves surface finish as compared to continuous chips [39].

The preceding study revealed the relation of drilling process parameters with friction induced heat, chips morphology, size, and burr formation. The literature lacks to use fuzzy logic approach to validate drill induced temperature at the tool-chip interaction zone while changing cutting speed and feed rate. The study aims to presents the Mamdani fuzzy inference system for the prediction of maximum temperature rise in drilling zone at varying cutting conditions. The results of fuzzy logic are validated and mapped with experimental results which further demonstrates the effectiveness of fuzzy model. Cryogenic cooling technique will be very easy to apply if temperature profile during cutting is known. From the temperature study, thermal and viscous properties of coolant can be decided during wet machining. Further, chips' morphology and burrs' formation in the drilled hole is also studied in correspondence with varying drilling conditions. 


\section{Materials and Methods}

2.1. Fuzzy-Based Algorithm for Calculation of Maximum Temperature during Drilling of AISI 1018 Steel

A conceptual illustration of the developed fuzzy-based algorithm to calculate the maximum temperature produced at various machining input parameters in drilling of AISI 1018 steel is shown in Figure 1.

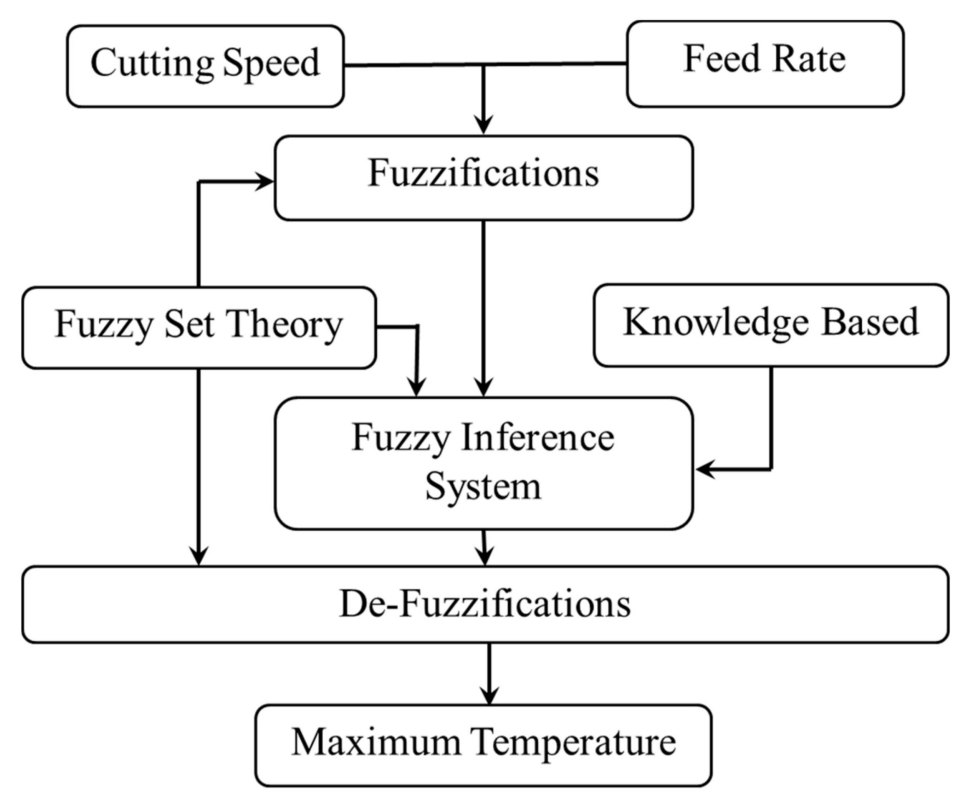

Figure 1. Schematic illustration of the developed fuzzy algorithm.

The developed fuzzy inference system is designed for two input variables-speed and feed rate-predicting the maximum temperature in the drilling process as an output parameter. The input variables are fed to the fuzzy plane and the maximum temperature is determined based on the defined fuzzy rules-based system. Moreover, in the developed algorithm, the outputs calculation of the scheme is based on the centroid method and de-fuzzification is accomplished using Mamdani implication.

\subsubsection{Fuzzy Membership Functions}

In the current work, a triangular membership function was used for the input (cutting speed, feed rate) and output (maximum temperature) variables. The selection was made based on the recommendation of (Pedrycz, 1994) [40]. The triangular function is mathematically represented as in Equation (1):

$$
T, \quad S, \quad F R(a, m, b)=\left\{\begin{array}{cc}
0 & x \leq a \\
\frac{x-a}{m-a} & a<x \leq m \\
\frac{b-x}{b-m} & m<x \leq b \\
0 & x \geq b
\end{array}\right.
$$

where ' $T$ ' represent temperature, ' $S$ ' and ' $F R$ ' are cutting speed and feed rate, respectively. $a, m$, and $b$ represent the triangular membership function and details can be found elsewhere [8].

\subsubsection{Fuzzy Sets}

The two input variables—cutting speed and feed rate-are divided into five fuzzy sets: low (L), medium low (ML), medium (M), medium high (MH), and high (H). In addition, maximum temperature generated in the drilling operation as an output variable is divided into 9 fuzzy sets: very-very low (VVL), very-low (VL), low (L), medium-low (ML), 
medium $(\mathrm{M})$, medium-high $(\mathrm{MH})$, high $(\mathrm{H})$, very-high $(\mathrm{VH})$, and very-very high $(\mathrm{VVH})$. The associated membership function with the defined fuzzy sets for input and output variables is presented in Figures 2 and 3, respectively. Similarly, additional information about the defined fuzzy sets for input and output variables and terminologies used for them are listed in Table 1.

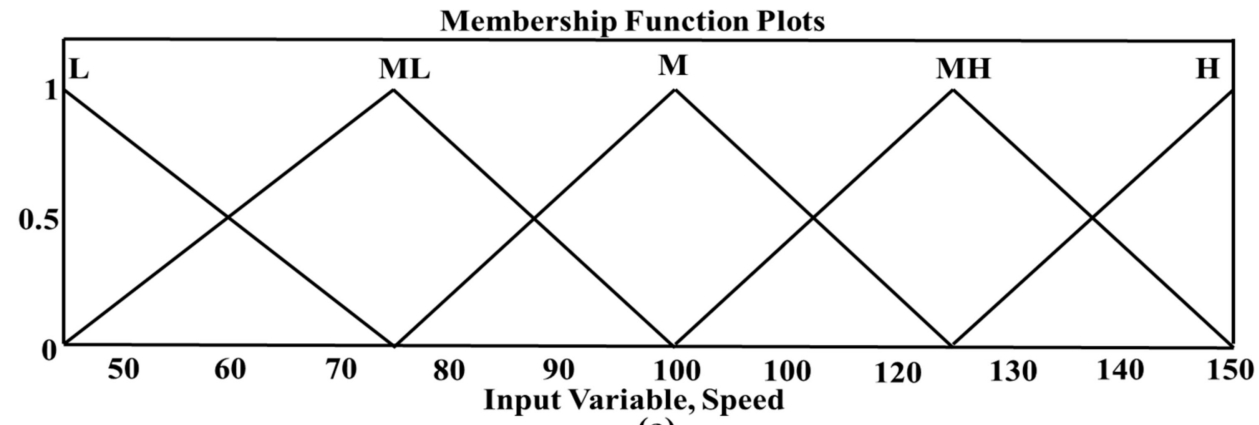

(a)

Membership Function Plots

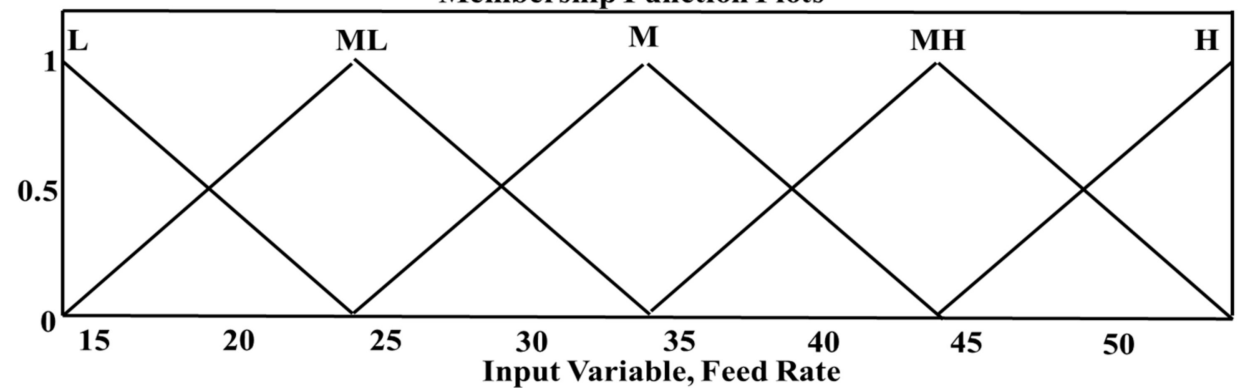

(b)

Figure 2. Input membership functions used in Fuzzy Logic System (FLS): (a) speed, (b) feed rate.

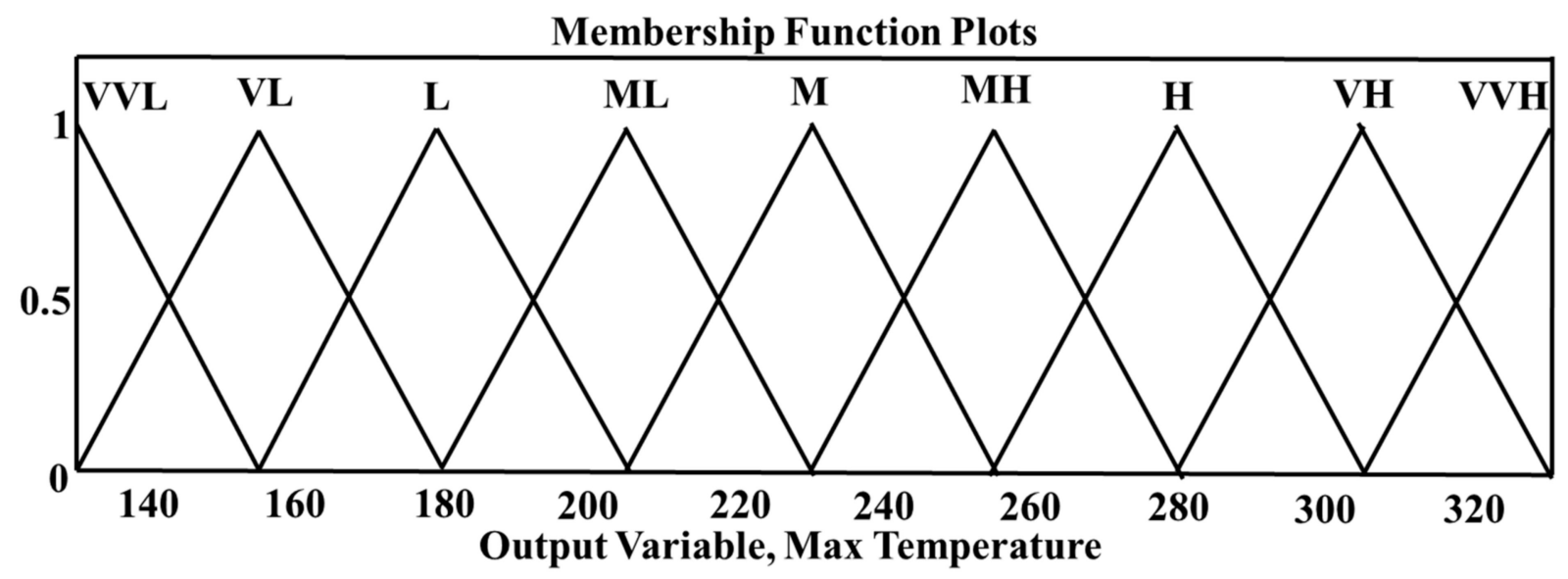

Figure 3. Output membership function used in FLS.

\subsubsection{Proposed Rules}

For the decision making of the output variable (maximum temperature) with respect to the various combinations of input variables (speed and feed), a rule-based system was defined for the developed fuzzy inference system. The details of the rule-based system used in the developed FIS are listed in Table 2. 
Table 1. Input and output parameters used in fuzzy inference system (FIS).

\begin{tabular}{|c|c|c|c|c|c|c|c|c|}
\hline \multirow{3}{*}{ MF Type } & \multicolumn{5}{|c|}{ Fuzzy Input } & \multirow{2}{*}{\multicolumn{3}{|c|}{$\frac{\text { Fuzzy Output }}{\text { Maximum Temperature }}$}} \\
\hline & \multirow{2}{*}{ Variable } & \multicolumn{2}{|c|}{ Cutting Speed } & \multicolumn{2}{|c|}{ Feed Rate } & & & \\
\hline & & Parameter & Range & Parameter & Range & Variable & Parameter & Range \\
\hline \multirow{9}{*}{ Triangular } & $\mathrm{L}$ & [45 45 75] & [45 150] & [14 14 24] & [14 54] & VVL & {$\left[\begin{array}{lll}130 & 130 & 155\end{array}\right]$} & {$\left[\begin{array}{lll}130 & 330\end{array}\right]$} \\
\hline & ML & [45 75 100] & [45 150] & [14 24 34] & [14 54] & VL & {$\left[\begin{array}{lll}130 & 155 & 180\end{array}\right]$} & {$\left[\begin{array}{lll}130 & 330\end{array}\right]$} \\
\hline & $\mathrm{M}$ & [75 100 125] & [45 150] & [24 3444$]$ & [14 54] & $\mathrm{L}$ & {$\left[\begin{array}{lll}155 & 180 & 205\end{array}\right]$} & [130 330] \\
\hline & $\mathrm{MH}$ & [100 125 150] & [45 150] & [34 44 54] & [14 54] & ML & {$\left[\begin{array}{lll}180 & 205 & 230\end{array}\right]$} & [130 330] \\
\hline & $\mathrm{H}$ & [125 150 150] & [45 150] & [44 54 54] & [14 54] & $\mathrm{M}$ & {$\left[\begin{array}{lll}205 & 230 & 255\end{array}\right]$} & {$\left[\begin{array}{lll}130 & 330\end{array}\right]$} \\
\hline & & & & & & MH & {$\left[\begin{array}{lll}230 & 255 & 280\end{array}\right]$} & [130 330] \\
\hline & & & & & & $\mathrm{H}$ & {$\left[\begin{array}{llll}255 & 280 & 305\end{array}\right]$} & [130 330] \\
\hline & & & & & & $\mathrm{VH}$ & {$\left[\begin{array}{llll}280 & 305 & 330\end{array}\right]$} & [130 330] \\
\hline & & & & & & VVH & [305 330 330] & [130 330] \\
\hline
\end{tabular}

Table 2. The fuzzy rules developed for the current FIS.

\begin{tabular}{|c|c|c|c|c|c|c|c|}
\hline \multirow[t]{2}{*}{ Rules } & \multicolumn{2}{|c|}{ Input } & \multirow{2}{*}{$\begin{array}{c}\text { Output } \\
\text { Maximum Temperature }\end{array}$} & \multirow[t]{2}{*}{ Rules } & \multicolumn{2}{|c|}{ Input } & \multirow{2}{*}{$\begin{array}{c}\text { Output } \\
\text { Maximum Temperature }\end{array}$} \\
\hline & Speed & Feed Rate & & & Speed & Feed Rate & \\
\hline R1 & $\mathrm{L}$ & $\mathrm{L}$ & VVL & $\mathrm{R} 2$ & $\mathrm{~L}$ & $\mathrm{M}$ & VL \\
\hline R3 & $\mathrm{L}$ & $\mathrm{MH}$ & $\mathrm{ML}$ & $\mathrm{R} 4$ & $\mathrm{~L}$ & $\mathrm{H}$ & $\mathrm{M}$ \\
\hline $\mathrm{R} 5$ & $\mathrm{~L}$ & ML & VL & R6 & ML & $\mathrm{L}$ & VL \\
\hline R7 & ML & ML & $\mathrm{L}$ & R8 & ML & M & ML \\
\hline R9 & ML & $\mathrm{MH}$ & $\mathrm{M}$ & R10 & ML & $\mathrm{H}$ & $\mathrm{MH}$ \\
\hline R11 & $\mathrm{M}$ & $\mathrm{L}$ & ML & R12 & $\mathrm{M}$ & ML & ML \\
\hline R13 & M & M & $\mathrm{M}$ & R14 & $\mathrm{M}$ & $\mathrm{MH}$ & $\mathrm{MH}$ \\
\hline R15 & $\mathrm{M}$ & $\mathrm{H}$ & $\mathrm{VH}$ & $\mathrm{R} 16$ & MH & $\mathrm{L}$ & $\mathrm{M}$ \\
\hline R17 & MH & $\mathrm{ML}$ & $\mathrm{M}$ & R18 & $\mathrm{MH}$ & M & MH \\
\hline R19 & MH & $\mathrm{MH}$ & $\mathrm{H}$ & $\mathrm{R} 20$ & $\mathrm{MH}$ & $\mathrm{H}$ & $\mathrm{VVH}$ \\
\hline $\mathrm{R} 21$ & $\mathrm{H}$ & ML & MH & $\mathrm{R} 22$ & $\mathrm{H}$ & $\mathrm{M}$ & $\mathrm{VH}$ \\
\hline $\mathrm{R} 23$ & $\mathrm{H}$ & $\mathrm{MH}$ & $\mathrm{VH}$ & $\mathrm{R} 24$ & $\mathrm{H}$ & $\mathrm{H}$ & VVH \\
\hline $\mathrm{R} 25$ & $\mathrm{H}$ & $\mathrm{L}$ & $\mathrm{M}$ & & & & \\
\hline
\end{tabular}

\subsection{Experimental Material and Procedure}

The developed model is validated through experimentation conducted on the selected drilling input parameters; cutting speeds $(45,80,145 \mathrm{rpm})$ and feed rates $(14,35$, $50 \mathrm{~mm} / \mathrm{min}$ ) were selected from the range of input variables used in FIS algorithm. The cutting input parameters were decided based on the recommendations stipulated in American Society for Metals handbook for machining [41].

The AISI 1018 mild steel blocks were used in this study. The AISI 1018 block is cut into blocks of required dimensions using a power hack saw followed by a filing operation to remove burrs and uneven surface. Parameters of workpiece for drilling are descripted in Table 3. The elemental composition of AISI 1018 steel provided by the supplier is listed in Table 4. A titanium nitride (TiN) coated high speed steel drill bit with $4-6 \%$ cobalt is mostly used in drilling medium carbon steel because of its excellent performance and is used in the current study [28]. Titanium nitride (TiN) coated high speed steel drill bit with 4-6\% cobalt and $30^{\circ}$ helix angles is used to experimentally validate the FIS simulated results. The same drill bit having $10 \mathrm{~mm}$ diameter is dry-drilled in mild steel blocks. The material and geometric specifications of the drill bit are shown in Table 5. 
Table 3. Elemental composition of AISI 1018 steel in weight \%.

\begin{tabular}{cc}
\hline Elements & Weight $\%$ \\
\hline $\mathrm{Fe}$ & Bal \\
\hline $\mathrm{C}$ & 0.22 \\
\hline $\mathrm{Mn}$ & $0.5-0.6$ \\
\hline $\mathrm{Si}$ & 0.21 \\
\hline $\mathrm{Cr}$ & 0.162 \\
\hline $\mathrm{P}$ & $0.001-0.003$ \\
\hline
\end{tabular}

Table 4. AISI 1018 workpiece parameters.

\begin{tabular}{cc}
\hline Workpiece Parameters & Description \\
\hline Material & AISI 1018 mild steel \\
\hline Geometric shape & Rectangular cube \\
\hline Dimensions & $60 \mathrm{~mm} \times 60 \mathrm{~mm} \times 25 \mathrm{~mm}$ \\
\hline Thickness & $10 \mathrm{~mm}$ \\
\hline Hardness & $72 \mathrm{HRB}$ \\
\hline
\end{tabular}

Table 5. Drill bit material and geometric descriptions.

\begin{tabular}{cc}
\hline Drill Bit Parameters & Description \\
\hline Manufacturer & Norseman Drill and Tool (USA) \\
\hline Type & 260AN \\
\hline Material & High speed steel with 4-6\% cobalt \\
\hline Coating & Titanium Nitride (TiN) \\
\hline Helix angle & $30^{\circ}$ \\
\hline Point angle & $118^{\circ}$ \\
\hline Diameter & $10 \mathrm{~mm}$ \\
\hline
\end{tabular}

Using a conventional milling machine (Model: Victoria-Elliott U2, London, UK), three holes of $10 \mathrm{~mm}$ depth were drilled for each combination set of drilling conditions to statistically validate the concluded results. The selected drilling parameters used in the experimentation are presented in Table 6, which are the same as those used in fuzzy logic modeling.

Table 6. Cutting parameters of drilling.

\begin{tabular}{cccc}
\hline Level & $\mathbf{1}$ & $\mathbf{2}$ & $\mathbf{3}$ \\
\hline Cutting Speed $(\mathrm{rpm})$ & 45 & 80 & 145 \\
\hline Feed rate $(\mathrm{mm} / \mathrm{min})$ & 14 & 35 & 50 \\
\hline Drilling Depth $(\mathrm{mm})$ & & 10 & \\
\hline
\end{tabular}

The AISI 1018 steel blocks shown in Figure 4 are dry-drilled and maximum and changing temperature profiles under varying conditions were recorded using an infrared pyrometer sensor (Model: OS-180-USB-LSTL, OMEGA, London, UK). The experimental setup is depicted in Figure 5. 


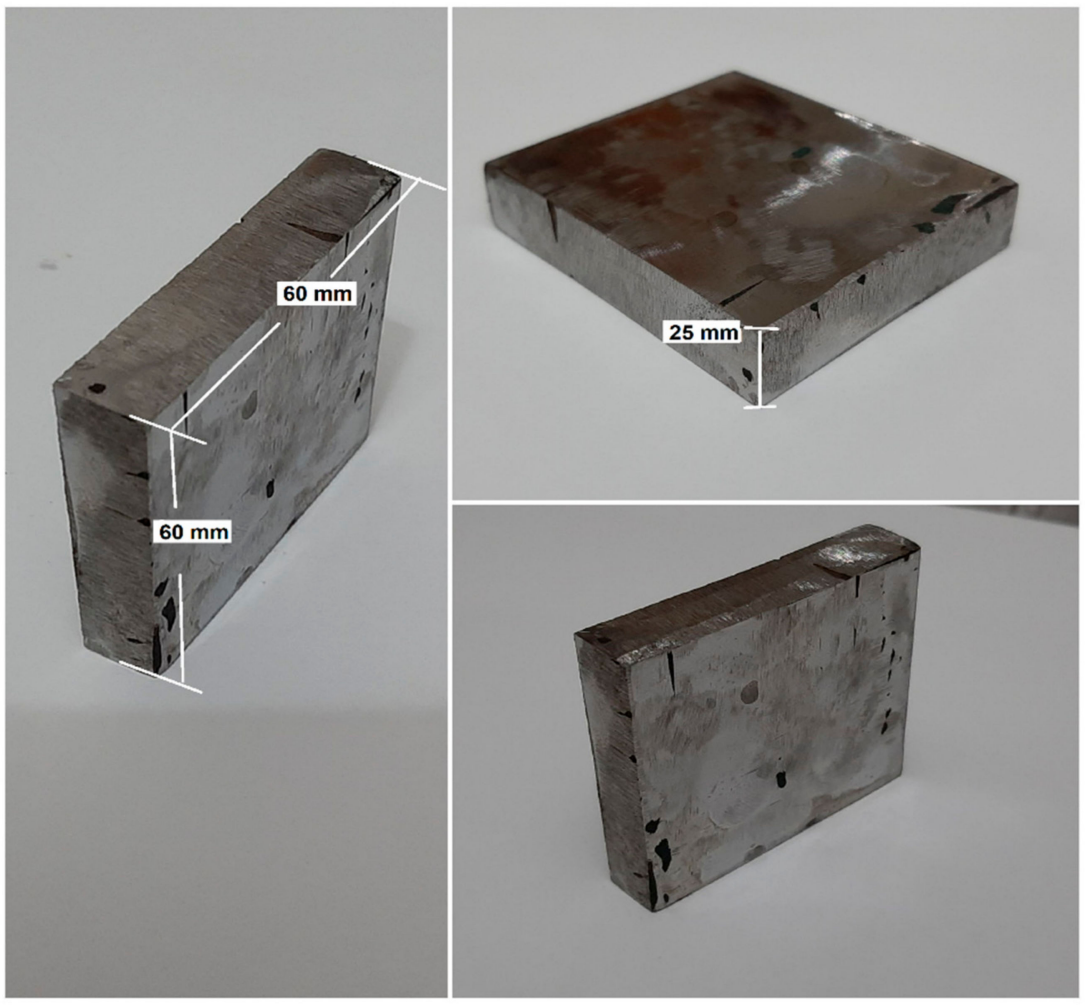

Figure 4. Sample of AISI 1018 steel blocks.
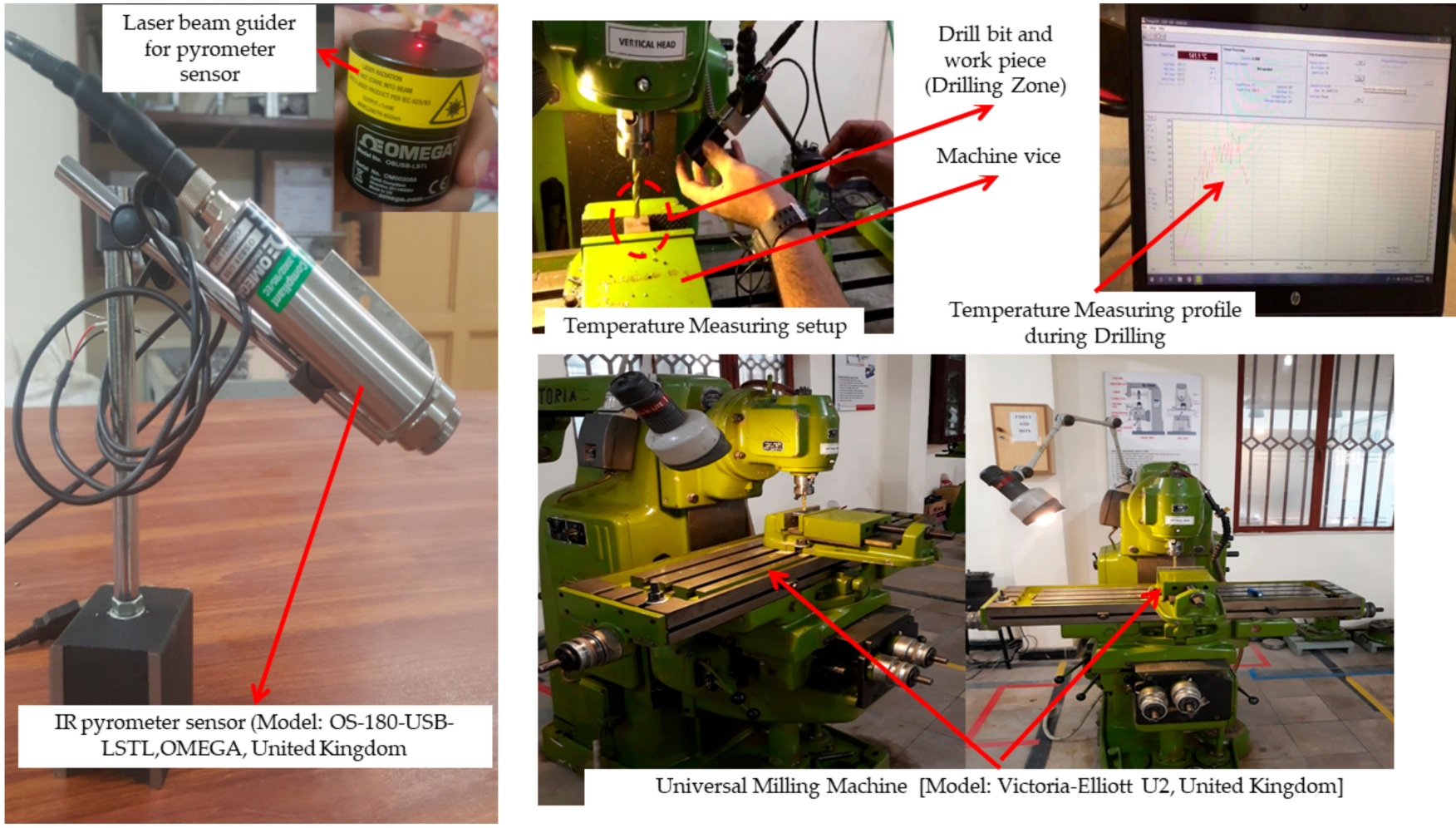

- Temperature Measuring setup

Temperature Measuring profile

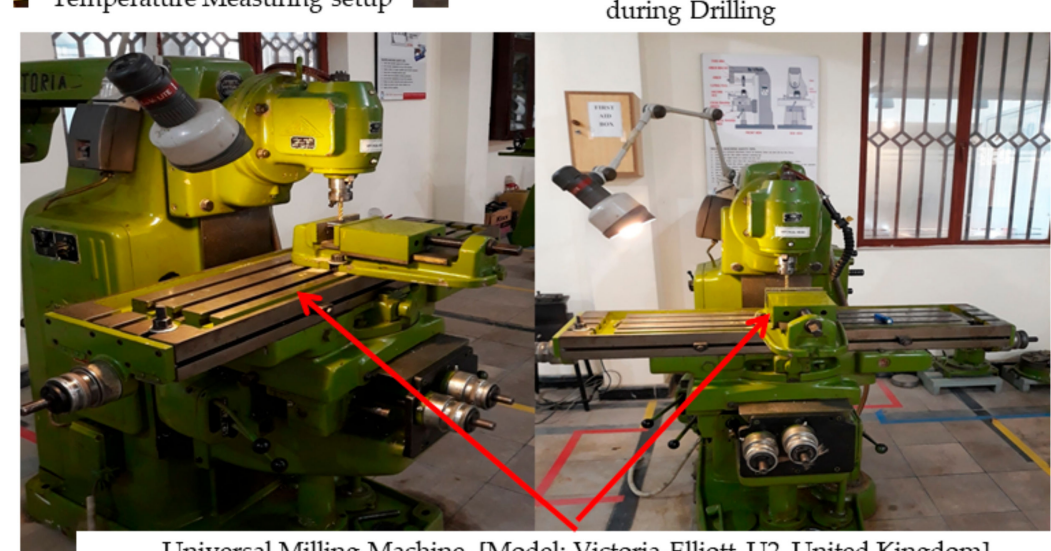

Universal Milling Machine [Model: Victoria-Elliott U2, United Kingdom]

Figure 5. Experimental setup for temperature measurements.

For infrared pyrometer, surface emissivity of AISI 1018 mild steel block with relatively rough surface is found experimentally at different temperatures. Prior to noting live temperatures during drilling, the sensor was calibrated for emissivity value. A series of 
experiments were conducted to find the emissivity value for the AISI 1018 material because it varies with temperature. It is cross checked and verified with thermocouple reading at various temperature. The emissivity value as the function of temperature is shown in Figure 6 and then average value is taken, i.e., $\mathrm{E}=0.23$. The pyrometer is calibrated and set with average E-value. The same method for calculating emissivity value for pyrometer calibration is followed by Riaz et al. [42,43]. A magnetic stand is used to mount and clamp the pyrometer and set it at the recommended distance from the target surface to be drilled. The sensor is mounted in such a way that it can easily move up and down with the worktable of the milling machine. Laser beam of the pyrometer is precisely targeted on the tool-job interface to note instant temperature values after each second. Temperature values were recorded in built-in software, i.e., 'Omega soft' interfaced through a USB port with a CPU unit. The values were then plotted in Microsoft Excel.

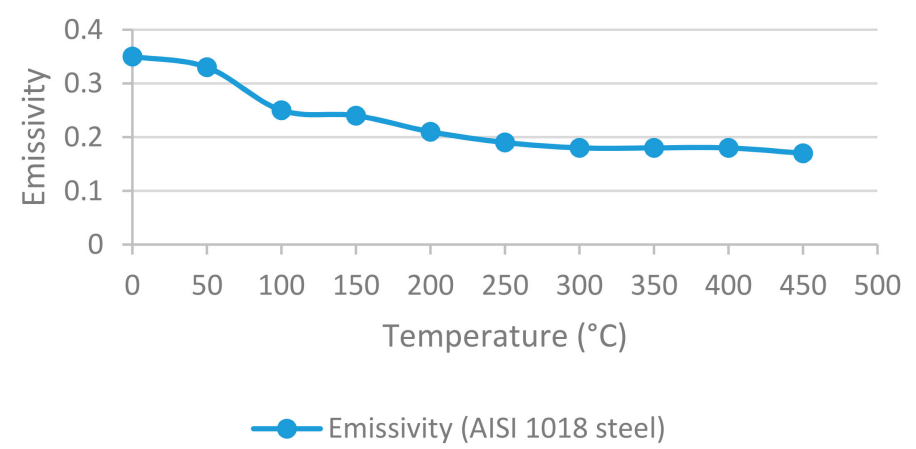

Figure 6. Emissivity as function of temperature for AISI 1018 steel.

Additionally, the chips were collected to study the chips morphology, type, and size for each combination of drilling conditions shown in Table 7. Furthermore, burr formation is also discussed for each case and concluded accordingly.

Table 7. Drilling parameters and results of maximum temperature rise during dry-drilling for each set of cutting conditions.

\begin{tabular}{|c|c|c|c|c|c|c|c|c|c|c|}
\hline \multirow[b]{2}{*}{ S \# } & \multirow{2}{*}{$\begin{array}{c}\text { Cutting } \\
\text { Speed } \\
\text { (rpm) }\end{array}$} & \multirow{2}{*}{$\begin{array}{l}\text { Feed Rate } \\
(\mathrm{mm} / \mathrm{min})\end{array}$} & \multirow[b]{2}{*}{ Specimen } & \multirow{2}{*}{$\begin{array}{l}\text { No. of } \\
\text { Holes } \\
\text { Drilled }\end{array}$} & \multirow{2}{*}{$\begin{array}{l}\text { Drilling } \\
\text { Depth } \\
(\mathrm{mm})\end{array}$} & \multirow{2}{*}{$\begin{array}{l}\text { Hole Di- } \\
\text { ameter } \\
(\mathrm{mm})\end{array}$} & \multicolumn{3}{|c|}{ Maximum Temperature $\left({ }^{\circ} \mathrm{C}\right)$} & \multirow[b]{2}{*}{ Average $\left({ }^{\circ} \mathrm{C}\right)$} \\
\hline & & & & & & & $\begin{array}{c}\text { Drill } \\
\text { Hole } 1\end{array}$ & $\begin{array}{c}\text { Drill } \\
\text { Hole } 2\end{array}$ & $\begin{array}{c}\text { Drill } \\
\text { Hole } 3\end{array}$ & \\
\hline 1 & 45 & \multirow{3}{*}{14} & 2 & 3 & 10 & 10 & 136 & 137 & 141 & 138 \\
\hline 2 & 80 & & 2 & 3 & 10 & 10 & 173 & 181 & 179 & 178 \\
\hline 3 & 145 & & 2 & 3 & 10 & 10 & 242 & 237 & 245 & 241 \\
\hline 4 & 45 & \multirow{3}{*}{35} & 2 & 3 & 10 & 10 & 172 & 165 & 159 & 165 \\
\hline 5 & 80 & & 2 & 3 & 10 & 10 & 204 & 212 & 215 & 210 \\
\hline 6 & 145 & & 2 & 3 & 10 & 10 & 272 & 285 & 280 & 279 \\
\hline 7 & 45 & \multirow{3}{*}{50} & 2 & 3 & 10 & 10 & 199 & 191 & 196 & 196 \\
\hline 8 & 80 & & 2 & 3 & 10 & 10 & 261 & 269 & 255 & 262 \\
\hline 9 & 145 & & 2 & 3 & 10 & 10 & 312 & 311 & 307 & 310 \\
\hline
\end{tabular}

\section{Results and Discussion}

\subsection{Simulations Results of Fuzzy Inference System (FIS)}

The commercially available fuzzy Logic Tool Box MATLAB ${ }^{\circledR}$ (R2014b) was used to simulate the developed model for temperature prediction in drilling of AISI 1018 steel. The developed algorithm has the capability to predict maximum temperature generated in drilling of the selected material at various speed-feed combinations within the defined range of input variables. 
In Figure 7, FIS results are simulated combinedly to predict maximum process induced temperatures at varying cutting speed for corresponding feed rate. It is depicted that maximum temperature increases with increasing corresponding feed rate. Similarly, the simulated FIS results for the corresponding cutting speed at varying feed rate are shown in Figure 8, which reflect the same increasing trend in process induced temperature with increase in cutting speed.

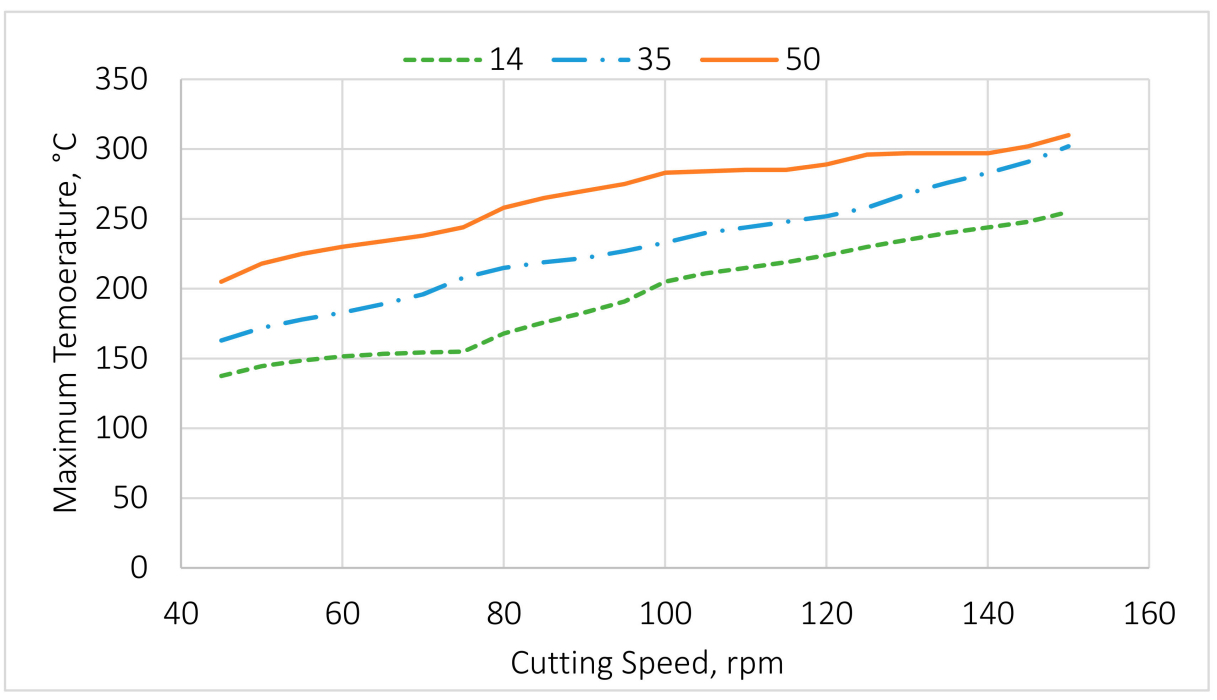

Figure 7. Simulation results for maximum temperature with changing cutting speeds at the defined feed rates $(14,35,50 \mathrm{~mm} / \mathrm{min})$ in drilling of AISI 1018 steel.

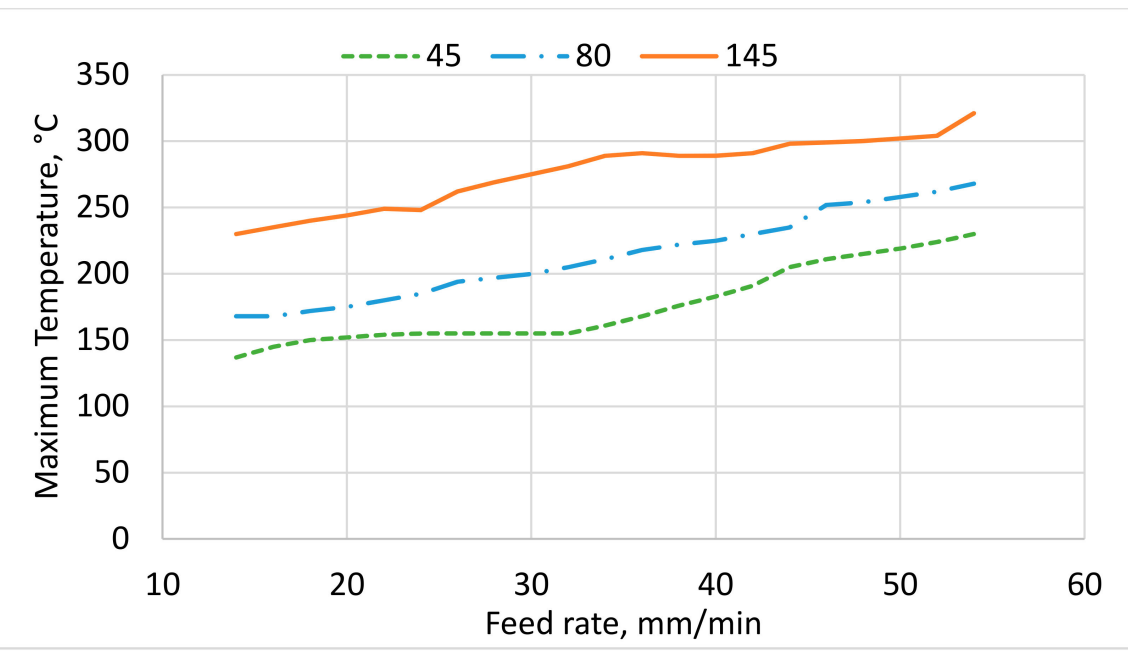

Figure 8. Simulation results for maximum temperature with changing feed rates at the defined cutting speeds $(45,80,145 \mathrm{rpm})$ in drilling of AISI 1018 steel.

\subsection{Maximum Temperature and Temperature Varying Trend}

Table 7 depicts maximum elevated temperature against each set of drilling parameters. Each drilling condition is tested thrice and then the average value is shown in the same table. The succeeding graphs in Figure 9 show temperature changing trend at the tool-job contact zone for all nine sets of drilling experiments. Drilling temperature was monitored using infra-radiation pyrometer. It is found that temperature increases with increase in cutting speed and feed rate. 

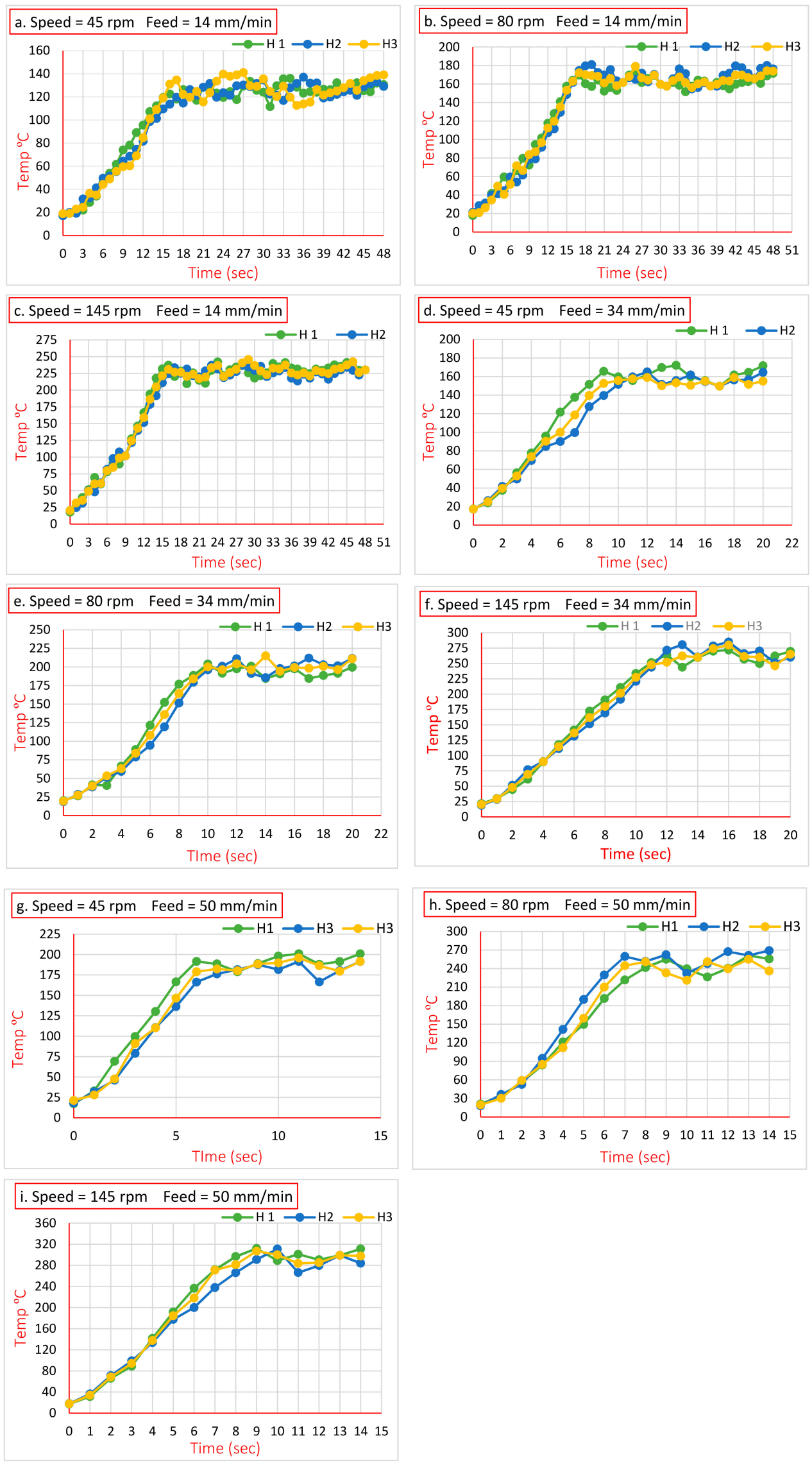

Figure 9. Temperature changing profiles during drilling for each set of cutting conditions (a-i). 
Drilling-induced temperature at the tool-job contact zone consistently increases from $20-25 \%$ when cutting speed increases from $45-80 \mathrm{rpm}$ and then from 80-145 rpm for any of the defined values of feed rate. It is concluded that percent rise in maximum temperature corresponding with cutting speed increases constantly with increase in cutting speed.

Likewise, temperature rise is $15-17 \%$ when feed rate increases from $14-34 \mathrm{~mm} / \mathrm{min}$ and then from $34-50 \mathrm{~mm} / \mathrm{min}$. It can be seen that rise in maximum temperature is comparatively less with increase in feed rate as compared to cutting speed.

It is noteworthy that rise in maximum temperature is evidenced with changing drilling speed and feed rate. If we compare percent rise in temperature w.r.t. drilling speed and feed rate, it is concluded that percent rise in temperature increases almost with constant rate with increasing tool speed and feed rate. Comparative rise in temperature with increasing drilling speed is more than feed rate.

\subsection{Burrs' Analysis}

The burr formation during hole drilling is visually observed. In wet drilling, the roll back during burr formation is absent, while in dry drilling, formation of roll back burr is an indication of temperature rise in the drilling zone [44]. As in drilling, no more cutting action exists in the final stages of through-hole drilling, so the remaining materials to be removed form roll back burrs rather than chips at the perimeter of the drilled hole. Due to burr formation at the hole periphery, heat dissipation limits due to low thermal conductivity of materials and rise in localized temperature in drilling zone increases.

Due to limited thermal conductivity, the material expands and results in roll back burr at the outer periphery. Size of roll back burr at the hole perimeter is dependent on the cutting condition and majorly on temperature rise. As it is observed from the noted temperature graphs, both drilling speed and feed rate contribute to heat generation at the cutting zone; therefore, at low feed and drilling speed, the burrs with roll back formation is less while it is significant at higher cutting speed and feed rates as shown in Figure 10. Instead of roll back, if we focus on height and thickness of burrs attached with hole periphery, they increase with increase in feed rate while cutting speed has no significant effect on burrs height and thickness. Burr removal requires an additional manufacturing operation for deburring which adds to product cost.

\subsection{Chips' Formation and Analysis}

Chip morphology is studied for the drilled chips at variable cutting speeds and feed rates. Chip morphology has meaningful importance in drilling and other turning processes. In this study, chips' morphology is noticed during drilling at varying time and cutting conditions. It is noticed that chips morphology and size remain unchanged with changing drilling depth but significant variation in size and morphology is noticed with varying drilling conditions. Figure 11 shows chip morphology found after drilling the sample at the defined cutting speeds and feed rates. Generally, long continuous chips are not desirable because of its disposal problem and manual removal of chips as it tangles around the drill body. In addition, continuous chips also cause clogging to chips flow. It is found that chips breaks when frictional torque between chips and hole wall exceeds the breaking torque of chip [45].

It is observed that when cutting speed increases, the size and continuity in the continuous spiral-shaped chips increases. The size approximately increases from $50-60 \mathrm{~mm}$ to 180-200 mm when cutting speed increases from 45-145 rpm. When the feed rate increases, the size as well the continuity in the chips decreases. The size decreases continuously from $50-60 \mathrm{~mm}$ to $10-15 \mathrm{~mm}$ as the feed rate increases from 14 to $50 \mathrm{~mm} / \mathrm{min}$. Further, chips' thickness reduces with increase in cutting speed but increases with feed rate. It is noticed that dry drilling leads to twisted chips because of low drill depth and no breaking action is exerted. In addition, it is noteworthy that surface finish comparatively degrades with increase in feed rate while it enhances with increasing drill bit cutting speeds. 
Speed $=45 \mathrm{rpm} \quad$ Feed $=14 \mathrm{~mm} / \mathrm{min}$

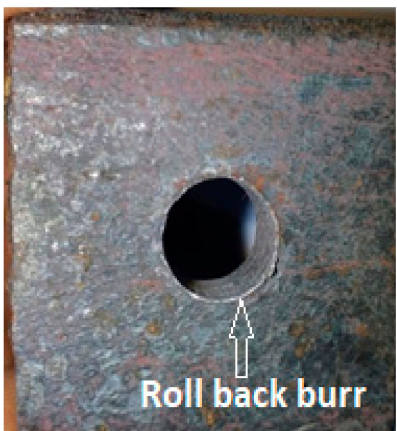

Speed $=45 \mathrm{rpm} \quad$ Feed $=34 \mathrm{~mm} / \mathrm{min}$

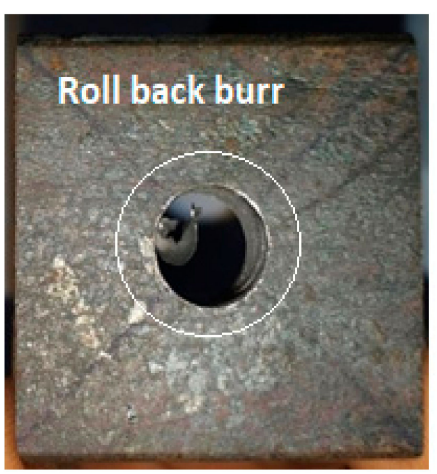

Speed $=45 \mathrm{rpm} \quad$ Feed $=50 \mathrm{~mm} / \mathrm{min}$

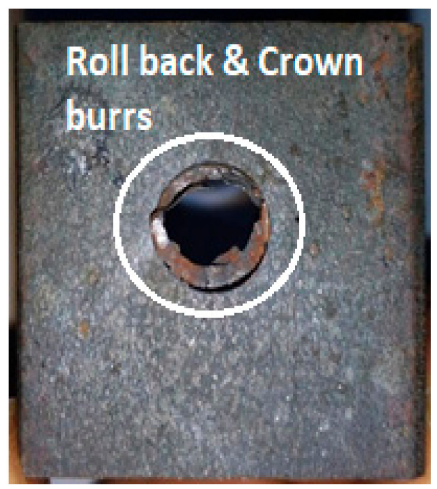

Speed $=80 \mathrm{rpm} \quad$ Feed $=14 \mathrm{~mm} / \mathrm{min}$

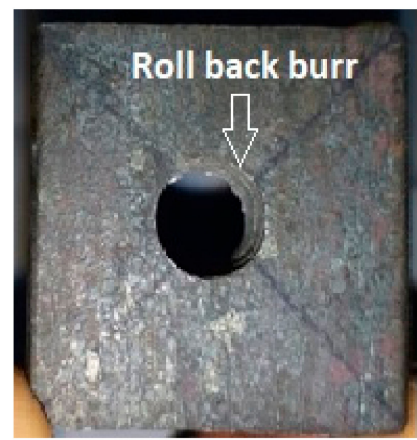

Speed $=80 \mathrm{rpm} \quad$ Feed $=34 \mathrm{~mm} / \mathrm{min}$

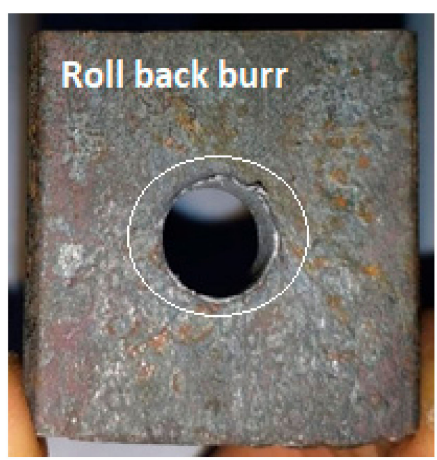

Speed $=80 \mathrm{rpm} \quad$ Feed $=50 \mathrm{~mm} / \mathrm{min}$ )

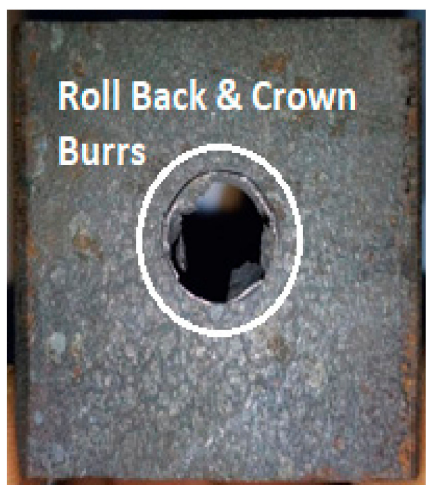

Speed $=145 \mathrm{rpm} \quad$ Feed $=14 \mathrm{~mm} / \mathrm{min}$

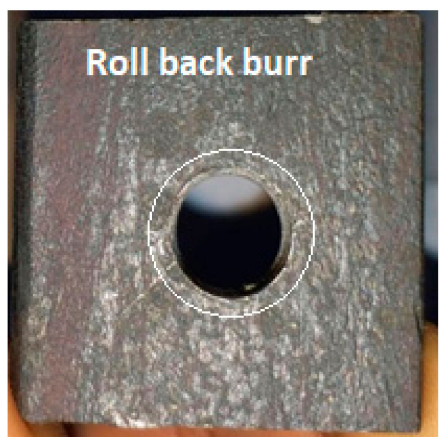

Speed $=145 \mathrm{rpm} \quad$ Feed $=34 \mathrm{~mm} / \mathrm{min}$

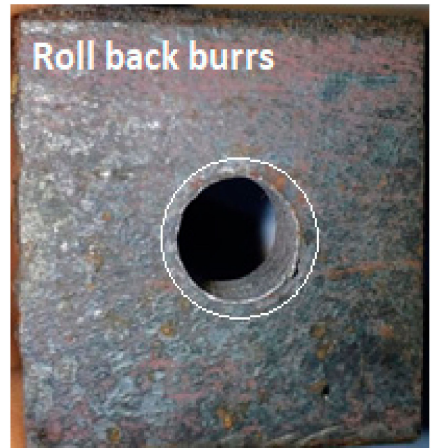

Speed $=145 \mathrm{rpm} \quad$ Feed $=50 \mathrm{~mm} / \mathrm{min}$

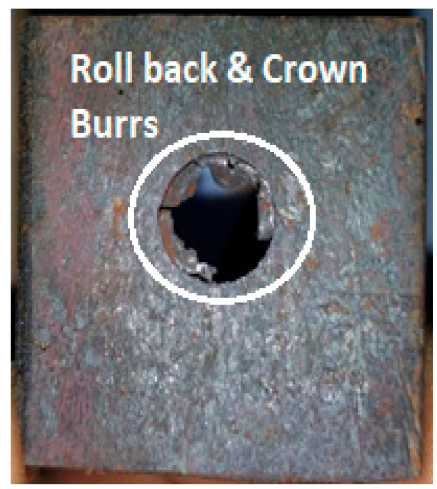

Figure 10. Burrs formation at varying cutting speeds and feed rates.

It is noticeable that segmental continuity in helical chip morphology is more at low feed rate as compared to higher feed rate. With increase in drill bit speed, the continuity in spiral chip ribbons increases unlike feed rates as depicted in Figure 11. It is also observed that chip radius increases with increase in feed rate and results in damaging of machined surface and causes burr formation while radius decreases with cutting speed along with improved hole surface.

\subsection{Comparison of Fuzzy Results with Experimental Values}

Experimental tests are essential at the defined fuzzy inputs for the results validation and verification obtained from FIS. Simulated results for maximum temperature using FIS are experimentally tested for its validation. Fuzzy results depict a strong trend resemblance with experimental values in which temperature increases with increase in cutting speed and feed rate. The average experimental values and fuzzy result is compared as shown in Figure 12 and depicts a small difference among all the noted values. Table 8 shows that experimental and simulated values are consistent and percent error is less than $6 \%$. 
The results further depict the accuracy of developed FIS for the prediction of maximum temperature during drilling process. A fairly acceptable bond and trend consistency is noticed between predicted and experimental values. This led us to the important conclusion that fuzzy based modeling and simulation is effective and feasible approach to simulate process induced maximum temperature in the drilling process.

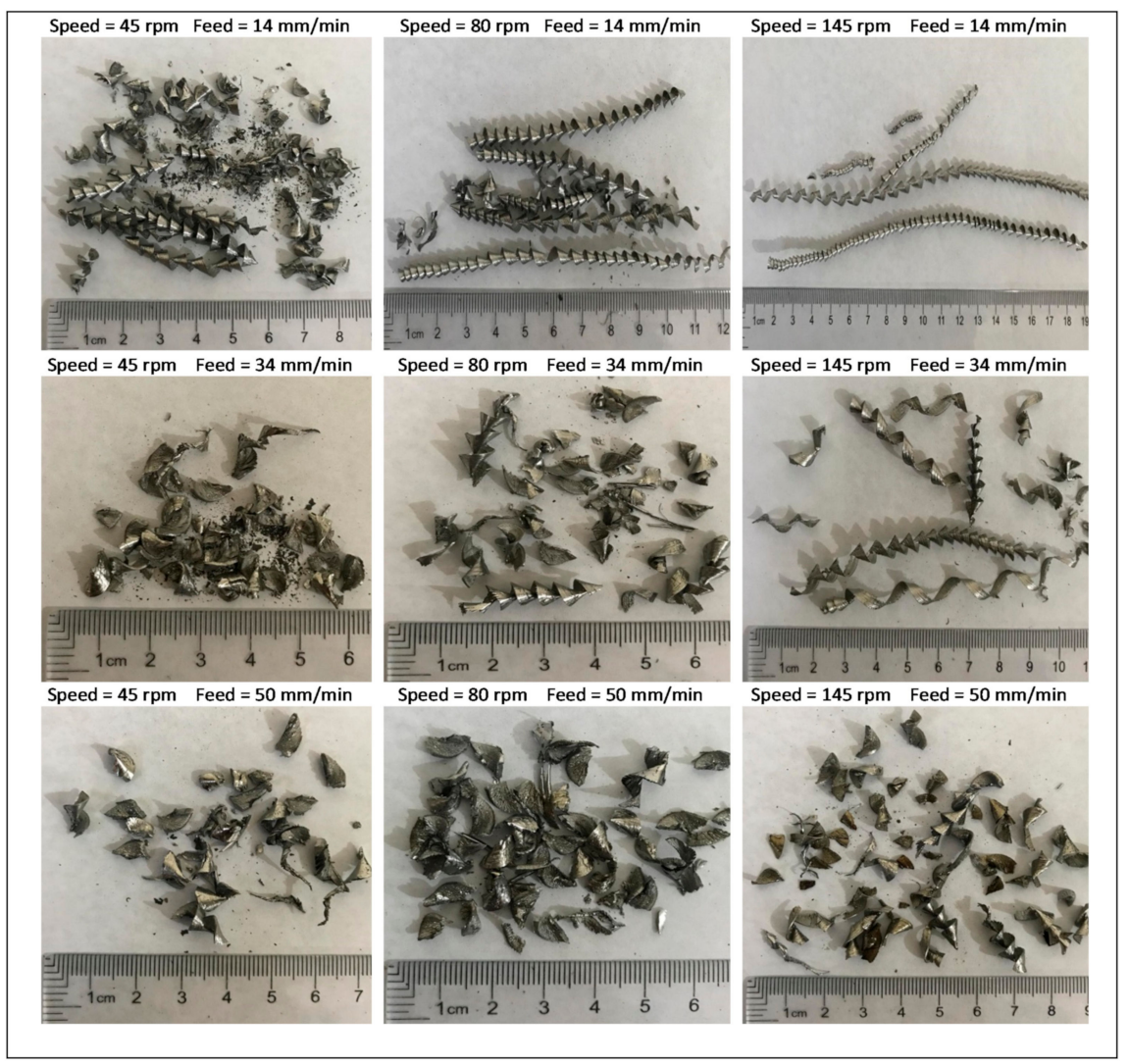

Figure 11. Chips morphology at varying cutting speeds and feed rates.

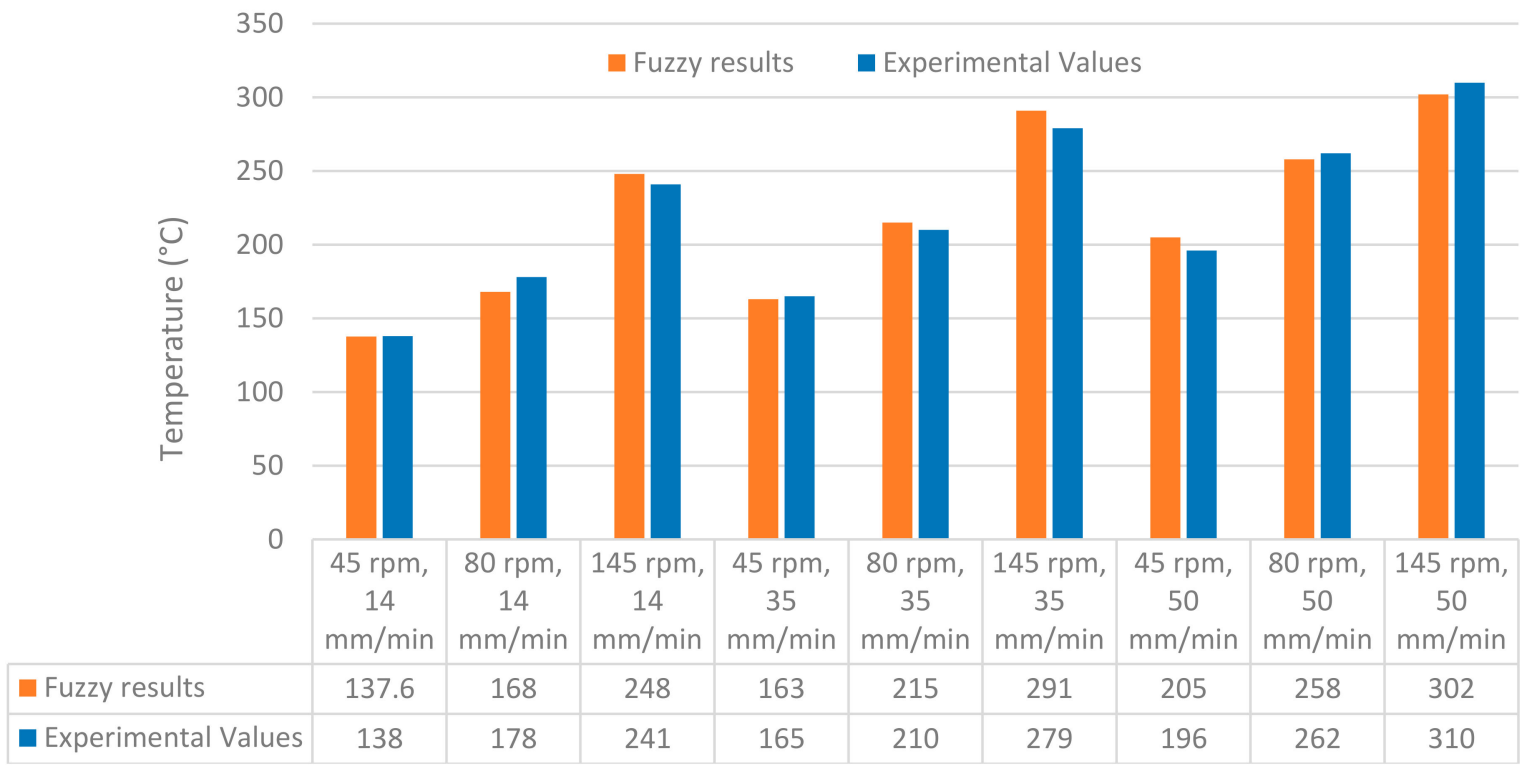

Figure 12. Comparison of fuzzy and experimental results. 
Table 8. Experimental and fuzzy results with percentage error for maximum drilling induced temperature at the tool-material contact zone.

\begin{tabular}{|c|c|c|c|c|c|c|c|c|c|c|}
\hline \multirow{2}{*}{ S \# } & \multirow{2}{*}{$\begin{array}{c}\text { Cutting } \\
\text { Speed (rpm) }\end{array}$} & \multirow{2}{*}{$\begin{array}{l}\text { Feed Rate } \\
(\mathrm{mm} / \mathrm{min})\end{array}$} & \multirow{2}{*}{$\begin{array}{l}\text { Drilling } \\
\text { Depth }(\mathrm{mm})\end{array}$} & \multirow{2}{*}{$\begin{array}{l}\text { Hole Diameter } \\
\quad(\mathrm{mm})\end{array}$} & \multicolumn{3}{|c|}{ Maximum Temperature $\left({ }^{\circ} \mathrm{C}\right)$} & \multirow{2}{*}{$\begin{array}{l}\text { Experimental Average Value of } \\
\text { Maximum Temperature }\left({ }^{\circ} \mathrm{C}\right)\end{array}$} & \multirow{2}{*}{ Fuzzy Results } & \multirow{2}{*}{$\%$ Error } \\
\hline & & & & & Drill Hole 1 & Drill Hole 2 & Drill Hole 3 & & & \\
\hline 1 & 45 & \multirow{2}{*}{14} & 10 & 10 & 136 & 137 & 141 & 138 & 137.6 & 0.217 \\
\hline 3 & 145 & & 10 & 10 & 242 & 237 & 245 & 241 & 248 & -2.933 \\
\hline 4 & 45 & \multirow{3}{*}{35} & 10 & 10 & 172 & 165 & 159 & 165 & 163 & 1.232 \\
\hline 5 & 80 & & 10 & 10 & 204 & 212 & 215 & 210 & 215 & -2.348 \\
\hline 6 & 145 & & 10 & 10 & 272 & 285 & 280 & 279 & 291 & -4.400 \\
\hline 7 & 45 & \multirow{3}{*}{50} & 10 & 10 & 199 & 191 & 196 & 196 & 205 & -4.841 \\
\hline 8 & 80 & & 10 & 10 & 261 & 269 & 255 & 262 & 258 & 1.426 \\
\hline 9 & 145 & & 10 & 10 & 312 & 311 & 307 & 310 & 302 & 2.496 \\
\hline
\end{tabular}




\section{Conclusions}

The following are the important conclusion of the study:

1. A model is developed based on Mamdani fuzzy inference system for the prediction of maximum temperature during drilling at varying cutting speeds and feed rates. Output temperature values of FIS are compared with experimental tests which revealed a good result match with an error less than $6 \%$. It is noticed that fuzzy-based modeling and simulation are effective and feasible to simulate process induced maximum temperature in the drilling process.

2. The simulated and experimental results reflect that temperature increases with increase in spindle speed and feed rate.

3. Drilling-induced temperature at the tool-job contact zone consistently increases from $20-25 \%$ when cutting speed increases from $45-80 \mathrm{rpm}$ and then from 80-145 rpm for any of the defined values of feed rate. It is concluded that percent rise in maximum temperature corresponding with cutting speed increases constantly with increase in cutting speed.

4. Likewise, temperature rise is $15-17 \%$, in particular, when feed rate increases from 14-34 $\mathrm{mm} / \mathrm{min}$ and then from $34-50 \mathrm{~mm} / \mathrm{min}$. it can be seen that rise in maximum temperature is comparatively less with increase in feed rate as compared to cutting speed.

5. Size of roll back burrs at the hole perimeter is dependent on the cutting condition and majorly on temperature rise. At low feed and cutting speed, the burrs with roll back formation is less while it is significant at higher drilling speeds and feed rates. Instead of roll back, if we focus on height and thickness of burrs attached with hole periphery, it increases with increase in feed rate while cutting speed has no significant effect on burr height and thickness.

6. It is observed that when cutting speed increases, the size and continuity in the continuous spiral-shaped chips increases. The size approximately increases from $50-60 \mathrm{~mm}$ to $180-200 \mathrm{~mm}$ when cutting speed increases from $45-145 \mathrm{rpm}$. When the feed rate increases, the size as well as the continuity in the chips decrease. The size decreases continuously from $50-60 \mathrm{~mm}$ to $10-15 \mathrm{~mm}$ as the feed rate increases from 14 to $50 \mathrm{~mm} / \mathrm{min}$. Further, chip thickness reduces with increase in cutting speed but increases with feed rate.

7. Segmental continuity in helical chip morphology is more at low feed rate as compared to higher feed rate. With increase in drilling speed, the continuity in spiral chip ribbons increases unlike feed rates.

8. Chip radius increases with increase in feed rate and results in damaging of machined surface and causes burr formation while radius decreases with cutting speed along with improved hole surface.

Author Contributions: Conceptualization, A.A.R. and R.M.; data curation, R.M. and N.U.; funding acquisition, M.A.; investigation, A.A.R. and R.M.; methodology, A.A.R. and R.M. and G.H.; Project administration, G.H.; visualization, N.U.; writing-original draft, A.A.R.; writing-review \& editing, G.H., M.A. and W.A. All authors have read and agreed to the published version of the manuscript.

Funding: The authors are grateful to the Raytheon Chair for Systems Engineering for funding.

Acknowledgments: The authors are grateful to the Raytheon Chair for Systems Engineering for funding. The authors would also like to acknowledge University of Engineering and Technology Peshawar and CECOS University of IT \& Emerging Sciences for providing the facility for this research work.

Conflicts of Interest: The authors declare that they have no conflict of interest. 


\section{References}

1. Shaikh, V.A.; Scharf, T.W.; Boubekri, N. Microlubrication machining of 1018 steel: The effect of a biodegradable lubricant on the microstructural integrity. Lubr. Sci. 2017, 29, 357-376. [CrossRef]

2. Neseli, S. Optimization of process parameters with minimum thrust force and torque in drilling operation using Taguchi method. Adv. Mech. Eng. 2014, 6, 925382. [CrossRef]

3. Kurt, M.; Bagci, E.; Kaynak, Y. Application of Taguchi methods in the optimization of cutting parameters for surface finish and hole diameter accuracy in dry drilling processes. Int. J. Adv. Manuf. Technol. 2009, 40, 458-469. [CrossRef]

4. Sun, D.; Lemoine, P.; Keys, D.; Doyle, P.; Malinov, S.; Zhao, Q.; Qin, X.; Jin, Y. Hole-making processes and their impacts on the microstructure and fatigue response of aircraft alloys. Int. J. Adv. Manuf. Technol. 2018, 94, 1719-1726. [CrossRef]

5. Mohan, N.S.; Ramachandra, A.; Kulkarni, S.M. Influence of process parameters on cutting force and torque during drilling of glass-fiber polyester reinforced composites. Compos. Struct. 2005, 71, 407-413. [CrossRef]

6. Anand, G.; Alagumurthi, N.; Elansezhian, R.; Palanikumar, K.; Venkateshwaran, N. Investigation of drilling parameters on hybrid polymer composites using grey relational analysis, regression, fuzzy logic, and ANN models. J. Braz. Soc. Mech. Sci. Eng. 2018, 40, 214. [CrossRef]

7. Latha, B.; Senthilkumar, V.S. Modeling and analysis of surface roughness parameters in drilling GFRP composites using fuzzy logic. Mater. Manuf. Process. 2010, 25, 817-827. [CrossRef]

8. Aamir, M.; Tu, S.; Tolouei-Rad, M.; Giasin, K.; Vafadar, A. Optimization and modeling of process parameters in multi-hole simultaneous drilling using taguchi method and fuzzy logic approach. Materials 2020, 13, 680. [CrossRef] [PubMed]

9. Ramesh, S.; Karunamoorthy, L.; Palanikumar, K. Fuzzy modeling and analysis of machining parameters in machining titanium alloy. Mater. Manuf. Process. 2008, 23, 439-447. [CrossRef]

10. Hashmi, K.; Graham, I.D.; Mills, B. Fuzzy logic based data selection for the drilling process. J. Mater. Process. Technol. 2000, 108, 55-61. [CrossRef]

11. Ranjan, J.; Patra, K.; Szalay, T.; Mia, M.; Gupta, M.K.; Song, Q.; Krolczyk, G.; Chudy, R.; Pashnyov, V.A.; Pimenov, D.Y. Artificial Intelligence-Based Hole Quality Prediction in Micro-Drilling Using Multiple Sensors. Sensors 2020, 20, 885. [CrossRef]

12. Upputuri, H.B.; Nimmagadda, V.S.; Duraisamy, E. Optimization of drilling parameters on carbon fiber reinforced polymer composites using fuzzy logic. Mater. Today Proc. 2020, 23, 528-535. [CrossRef]

13. Abhishek, K.; Datta, S.; Mahapatra, S.S. Optimization of thrust, torque, entry, and exist delamination factor during drilling of CFRP composites. Int. J. Adv. Manuf. Technol. 2015, 76, 401-416. [CrossRef]

14. Azmi, A.I. Design of fuzzy logic model for the prediction of tool performance during machining of composite materials. Procedia Eng. 2012, 38, 208-217. [CrossRef]

15. Rajasekaran, T.; Palanikumar, K.; Vinayagam, B.K. Application of fuzzy logic for modeling surface roughness in turning CFRP composites using CBN tool. Prod. Eng. 2011, 5, 191-199. [CrossRef]

16. Ladonne, M.; Cherif, M.; Landon, Y.; K'nevez, J.-Y.; Cahuc, O.; De Castelbajac, C. Modelling the vibration-assisted drilling process: Identification of influential phenomena. Int. J. Adv. Manuf. Technol. 2015, 81, 1657-1666. [CrossRef]

17. Li, X.; Meadows, A.; Babitsky, V.; Parkin, R. Experimental analysis on autoresonant control of ultrasonically assisted drilling. Mechatronics 2015, 29, 57-66. [CrossRef]

18. Bordin, A.; Sartori, S.; Bruschi, S.; Ghiotti, A. Experimental investigation on the feasibility of dry and cryogenic machining as sustainable strategies when turning Ti6Al4V produced by Additive Manufacturing. J. Clean. Prod. 2017, 142, $4142-4151$. [CrossRef]

19. Debnath, S.; Reddy, M.M.; Yi, Q.S. Environmental friendly cutting fluids and cooling techniques in machining: A review. J. Clean. Prod. 2014, 83, 33-47. [CrossRef]

20. Muhammad, R.; Ahmed, N.; Shariff, Y.M.; Silberschmidt, V.V. Effect of cutting conditions on temperature generated in drilling process: A FEA approach. In Advanced Materials Research; Trans Tech Publications Ltd.: Bäch SZ, Switzerland, 2011; Volume 223, pp. 240-246.

21. Moufki, A.; Molinari, A.; Dudzinski, D. Modelling of orthogonal cutting with a temperature dependent friction law. J. Mech. Phys. Solids 1998, 46, 2103-2138. [CrossRef]

22. Nouari, M.; List, G.; Girot, F.; Gehin, D. Effect of machining parameters and coating on wear mechanisms in dry drilling of aluminium alloys. Int. J. Mach. Tools Manuf. 2005, 45, 1436-1442. [CrossRef]

23. Rawat, S.; Attia, H. Characterization of the dry high speed drilling process of woven composites using Machinability Maps approach. CIRP Ann. 2009, 58, 105-108. [CrossRef]

24. Sato, M.; Aoki, T.; Tanaka, H.; Takeda, S. Variation of temperature at the bottom surface of a hole during drilling and its effect on tool wear. Int. J. Mach. Tools Manuf. 2013, 68, 40-47. [CrossRef]

25. Dewes, R.C.; Ng, E.; Chua, K.S.; Newton, P.G.; Aspinwall, D.K. Temperature measurement when high speed machining hardened mould/die steel. J. Mater. Process. Technol. 1999, 92, 293-301. [CrossRef]

26. Bağci, E.; Ozcelik, B. Investigation of the effect of drilling conditions on the twist drill temperature during step-by-step and continuous dry drilling. Mater. Des. 2006, 27, 446-454. [CrossRef]

27. Amini, S.; Khakbaz, H.; Barani, A. Improvement of near-dry machining and its effect on tool wear in turning of AISI 4142. Mater. Manuf. Process. 2015, 30, 241-247. [CrossRef] 
28. Ahsan, A.M.M.N.; Kibria, M.G.; Ahmed, M.R. An experimental study on the effect of minimum quantity lubrication on drilling AISI 1040 steel. GAZI Univ. J. Sci. 2015, 28, 161-167.

29. Bhowmick, S.; Alpas, A.T. The role of diamond-like carbon coated drills on minimum quantity lubrication drilling of magnesium alloys. Surf. Coat. Technol. 2011, 205, 5302-5311. [CrossRef]

30. Braga, D.U.; Diniz, A.E.; Miranda, G.W.A.; Coppini, N.L. Using a minimum quantity of lubricant (MQL) and a diamond coated tool in the drilling of aluminum-silicon alloys. J. Mater. Process. Technol. 2002, 122, 127-138. [CrossRef]

31. Maruda, R.W.; Legutko, S.; Krolczyk, G.M.; Raos, P. Influence of cooling conditions on the machining process under MQCL and MQL conditions. Teh. Vjesn. 2015, 22, 965-970. [CrossRef]

32. Amini, S.; Paktinat, H.; Barani, A.; Tehran, A.F. Vibration drilling of Al2024-T6. Mater. Manuf. Process. 2013, 28, 476-480. [CrossRef]

33. Amini, S.; Soleimani, M.; Paktinat, H.; Lotfi, M. Effect of longitudinal- torsional vibration in ultrasonic-assisted drilling. Mater. Manuf. Process. 2017, 32, 616-622. [CrossRef]

34. Bhowmick, S.; Alpas, A.T. Minimum quantity lubrication drilling of aluminium-silicon alloys in water using diamond-like carbon coated drills. Int. J. Mach. Tools Manuf. 2008, 48, 1429-1443. [CrossRef]

35. Lotfi, M.; Farid, A.A.; Soleimanimehr, H. A new hybrid model based on the radius ratio for prediction of effective cutting limit of chip breakers. Proc. Inst. Mech. Eng. Part B J. Eng. Manuf. 2016, 230, 1417-1427. [CrossRef]

36. Lotfi, M.; Farid, A.A.; Soleimanimehr, H. The effect of chip breaker geometry on chip shape, bending moment, and cutting force: FE analysis and experimental study. Int. J. Adv. Manuf. Technol. 2015, 78, 917-925. [CrossRef]

37. Bouacha, K.; Yallese, M.A.; Mabrouki, T.; Rigal, J.-F. Statistical analysis of surface roughness and cutting forces using response surface methodology in hard turning of AISI 52100 bearing steel with CBN tool. Int. J. Refract. Met. Hard Mater. 2010, 28, 349-361. [CrossRef]

38. Aurich, J.C.; Dornfeld, D.; Arrazola, P.J.; Franke, V.; Leitz, L.; Min, S. Burrs-Analysis, control and removal. CIRP Ann. 2009, 58, 519-542. [CrossRef]

39. Lotfi, M.; Amini, S.; Teimouri, R.; Alinaghian, M. Built-up edge reduction in drilling of AISI 1045 steel. Mater. Manuf. Process. 2017, 32, 623-630. [CrossRef]

40. Pedrycz, W. Why triangular membership functions? Fuzzy Sets Syst. 1994, 64, 21-30. [CrossRef]

41. Davis, J.R. Metals Handbook: Machining; ASM International: Almere, The Netherlands, 1989; ISBN 0871700220.

42. Riaz, A.A.; Hussain, G.; Ullah, N.; Wei, H.; Alkahtani, M.; Khan, M.N. An investigation on the effects of tool rotational speed and material temper on post-ISF tensile properties of Al2219 alloy. J. Mater. Res. Technol. 2020, 10, 853-867. [CrossRef]

43. Riaz, A.A.; Ullah, N.; Hussain, G.; Alkahtani, M.; Khan, M.N.; Khan, S. Experimental Investigations on the Effects of Rotational Speed on Temperature and Microstructure Variations in Incremental Forming of T6-Tempered and Annealed AA2219 Aerospace Alloy. Metals 2020, 10, 809. [CrossRef]

44. Dornfeld, D.A.; Kim, J.S.; Dechow, H.; Hewson, J.; Chen, L.J. Drilling burr formation in titanium alloy, Ti-6AI-4V. CIRP Ann. 1999, 48, 73-76. [CrossRef]

45. Sakurai, K.; Adachi, K.; Hanasaki, S. Breaking mechanism of chips in intermittently decelerated feed drilling of aluminum alloys. Keikinzoku 1998, 48, 195-198. 